\title{
Zoning of Iranian Heavy Precipitation Regime
}

\section{ART I C LE INF O}

\section{Article Type}

Original Research

\section{Authors}

Mohamadyariyan M. ${ }^{1} \mathrm{MA}$,

Tavosi T. ${ }^{* 1} P h D$,

Khosravi M. ${ }^{1} P h D$,

Hamidiyanpour M. ${ }^{1} \mathrm{PhD}$
How to cite this article Mohamadyariyan M, Tavosi T Khosravi M, Hamidiyanpour M. Zoning of Iranian Heavy Precipitation Regime. Geographical Researches Quarterly Journal. 2019; 34(2):183-192.
${ }^{1}$ Department of Geography and Environmental Planning University of Sistan and Baluchestan, Zahedan, Iran

\section{*Correspondence}

Address: Department of Geography and Environmental Planning, Natural Geography group, University of Sistan and Baluchestan, Zahedan , Iran. Postal Code:98135987

Phone: +98 (54) 31312491

Fax: +98 (54) 32416141

t.tavousi@gep.usb.ac.ir

\section{Article History}

Received: September 18, 2018

Accepted: April 15, 2019

ePublished: June 20, 2019

\section{A B S T R A C T}

Aims \& Backgrounds One of the most important incidents of heavy precipitation is the heavy loses. Heavy Precipitation regimes can help to identify the climate of each region. Many economic activities (especially agriculture) are adjusted based on the precipitation regime. Change of precipitation regime, in addition to significant environmental impacts, can affect the habits and economic activities and their incomes.

Identification of homogeneous precipitation regions is one of the most important prerequisites for environmental planning, especially resource management and spatial planning programs. This research aimed to zoning the Iranian Heavy precipitation regime over 20 years (1996-2016).

Methodology The daily precipitation data of 153 synoptic station were used to zoning the heavy precipitation regime. For implementation of the PCA model, a matrix with the dimensions of $153 \times 12$ was created. By analyzing the main components on the matrix, the first six components were selected. The stations were grouped in the six areas of homogeneous heavy precipitation by k-mean clustering of Standard score matrix of selective components.

Findings The regime of autumn heavy precipitation had the most factor score among the 6 regimes. The maximum heavy precipitation of spring-summer pattern (second pattern) was in April to July. The third pattern (absolute spring regime) had the highest heavy precipitation in April and May. The fourth pattern of early winter had the highest heavy precipitation in October, November, December, and January. In the fifth pattern, a large part of the heavy precipitation was in the summer. The heavy precipitation maximum of the sixth pattern was in the summer.

Conclusion There are 8 regimes of heavy precipitation in Iran which the maximum of heavy precipitation is in the Azerbaijani and north Azerbaijan regimes at the first half of the year and in the other regimes at the second half of the year.

Keywords Iran; Main Component Analysis; Multi-Average Clustering; Heavy Rainfall Regime; Equamax Rotation

\section{I T A T I O N L I N K S}

[Alexander, et al; 2006] Global observed changes in daily ...; [Alijani; 2001] Iran rainfall ...; [Alijani, et al; 2011] Atmospheric circulation patterns of ...; [Alijani; 2002] Synoptic ...; [Dinpashoh, et al; 2004] Selection of variables for the purpose ...; [Domroes \& Ranatung; 1993] A statistical approach toward a ...; [Domroes, et al; 1998] An analysis of regional and intra-annual ...; [Dostkamyan \& Mirmosavi; 2015] The study and analysis the clusters ...; [Farajzadeh-Asl; 1995] Drought analysis and forecasting ...; [Ghayoor, et al; 2011] Analysis of temporal and spatial events ...; [Janbaz Ghobadi, et al; 2011] Identify the patterns of severe winter ...; [Masoodian;2005] Identification of Iran's rainfall regime ...; [Masoodian; 1998] Investigating the system of temporal ...; [Masoudian \& Ataee; 2005] Identification of Iranian rainfall ...; [Masoodian; 2009] Precipitation regions of ...; [Modarres \& Sarhadi; 2011] Statisticallybased ...; [Mofidi, et al; 2007] Determination of the pattern of extreme ...; [Nazeri Tohroodi, et al; 2013] Comparison of normalizing ...; [Seibert, et al; 2007] Synoptic and regional patterns of ...; [Peterson, et al; 2001] Report on the activities of the working ...; [Raziei;2017] Identification of precipitation regimes of Iran using ...; [Raziei, et al; 2008] A precipitation-based regionalization for ...; [Raziei \& Azizi; 2007] The zoning of the western rainforest ...; [Regenmortel;1995] Regionalization of Botswana rainfall during ...; [Raziei; 2017] Identification of Iranian rainfall regimes ...; [Richman;1986] Rotation of principal ...; [Seibert, et al; 2007] Synoptic and regional patterns of heavy ...; [Yarnal; 1993] Synoptic climatology in environmental ...; [Zhang, et al; 2005] Trends in Middle East climate extreme ...; [Summer, et al; 1993] The spatial organization of daily rainfall over ...; [Bravo, et al; 2012] Cluster analysis for validated ...; [Jackson \& Weinand; 1995] Classification of tropical rainfall ...; [Kaufman \& Rousseuw;1990] Finding Groups in Data: An introduction to cluster ...; [Masoodian; 2004] Temperature trends in Iran during the last half ...; [Reiser \& Kutiel; 2007] The rainfall regime and its ...; [Romero, et al; 1999] A classification of the atmospheric circulation pattern producing significant daily ... 
از عناصر مهم در شناسايى اقليم هر منطقه است. رزيم بارش به

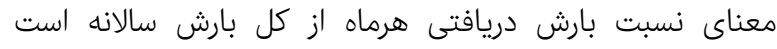

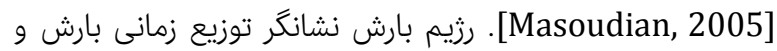

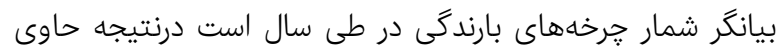

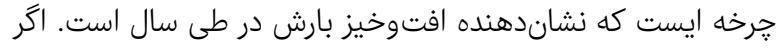

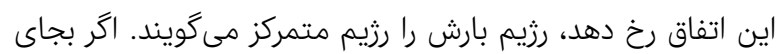

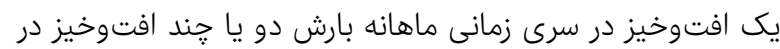

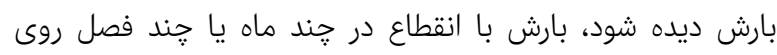
مىدهد. در اين صورت بارش غيرمتمركز خواهد بود. بسيارى از باز داهن

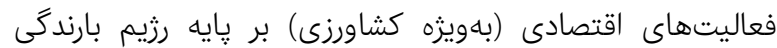

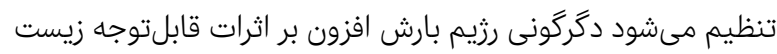

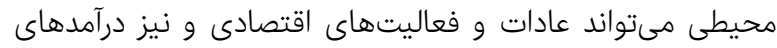
حاصل از آن را متأثر سازد. شناسايى مناطق همگً فئن بارشى مهمترين

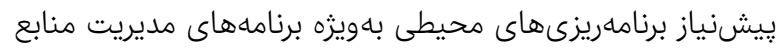

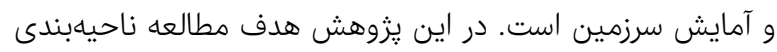
رزيمهاى بارش حدى است. براساس مطالعات و بررسىهاى صورت گرفته توسط نويسندگان

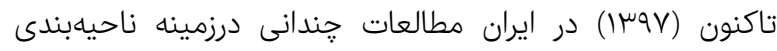
رثيمهاى بارشهاى حدى با دادههاى ايستخاهى صورت نكگرفته است. رجنمورتل [Regenmortel, 1995] بارشهاى بار روزانه

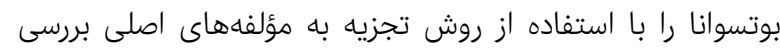

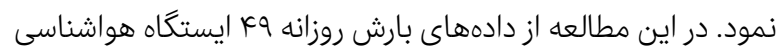

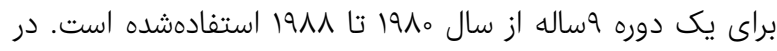
اين يزوهش با استفاده از جرخش واريماكس تجزيه به مؤلفههاى

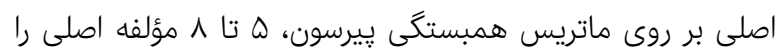

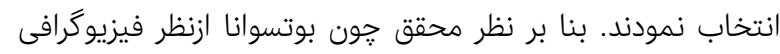

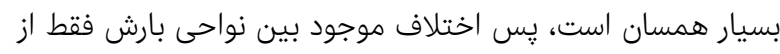

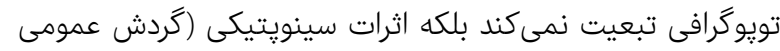

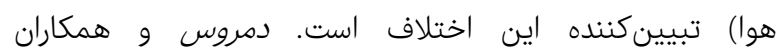
[Domroes et al, 1998] به روش تحليل مؤلفه اصلى و تحليل خوشهاى روى بارش ماهانه ا ايستخاه ايران سه مؤلفه اصلى و ينج

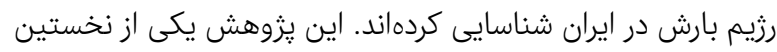

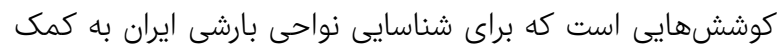

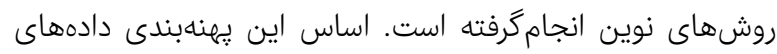

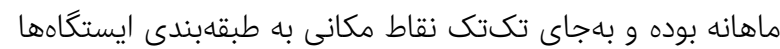

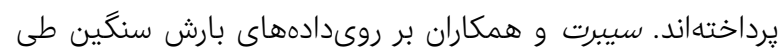

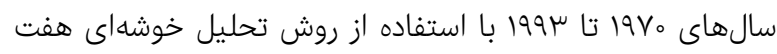
الكوى همديد و هفت ناحيه بارشى را در اتريش شناسايى كردند

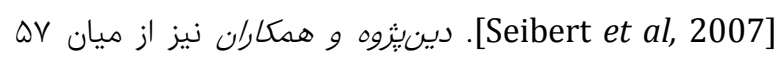
متغير اقليمى وابسته به بارش در VV ايستگاه همديدى و و

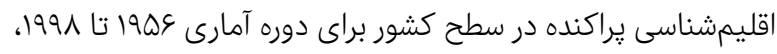

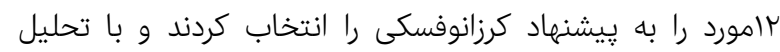

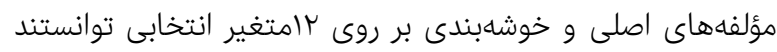

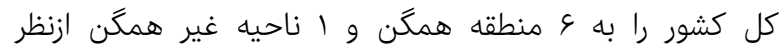

ناحيهبندى رزيم بارشهائ حدى ايران ايران در دوره

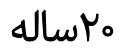

جكيده

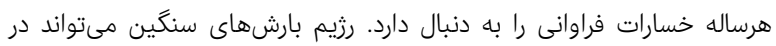

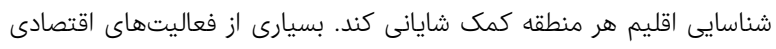

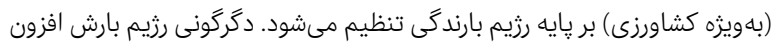

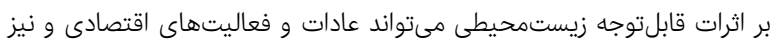

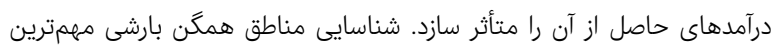

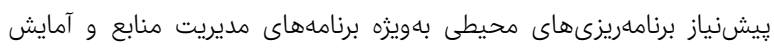

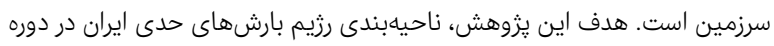

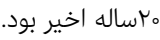

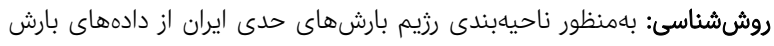

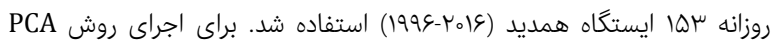

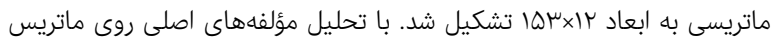

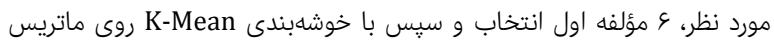

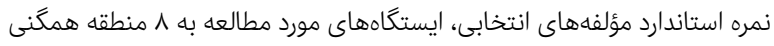

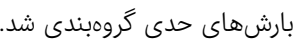

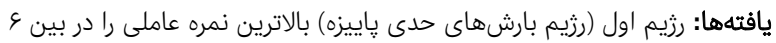

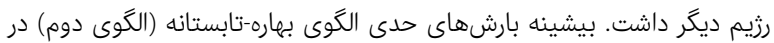

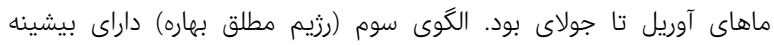

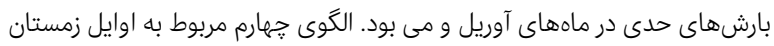

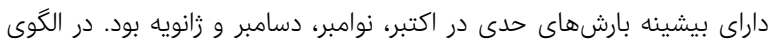

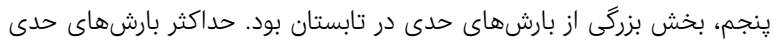

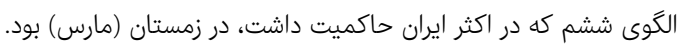

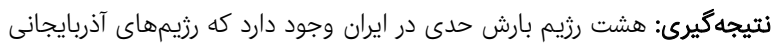

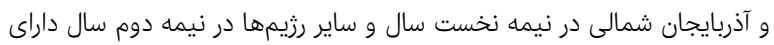

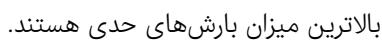

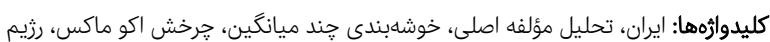
بارشهاى سنكين إنين

تاريخ دريافت: TV/o\&/TY تاريخ بذيرش: تاريخ: درياف: t.tavousi@gep.usb.ac.ir نويسنده مسئول: نائون:

مقدمه

شناسايى مناطق همگً اقليمى از ديرباز موردتوجه آب و هواشناسان

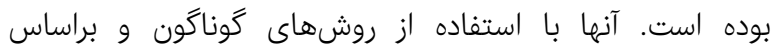

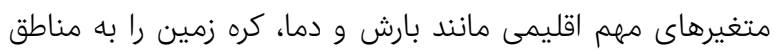

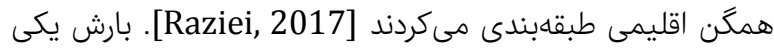




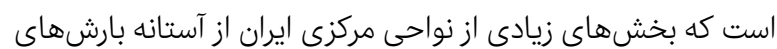

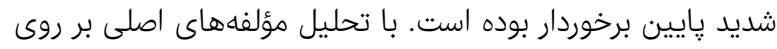

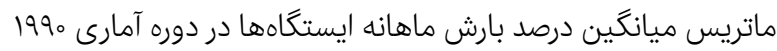

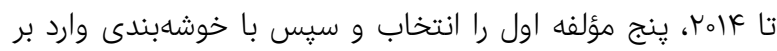

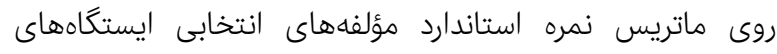

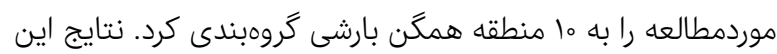

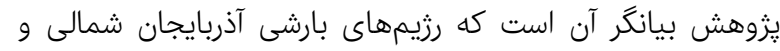

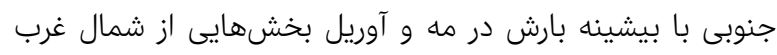

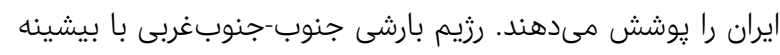

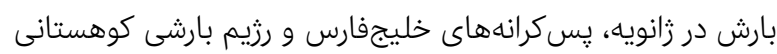

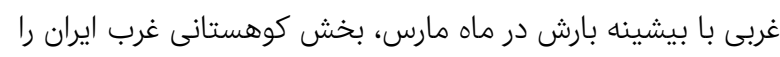

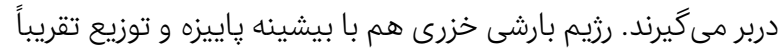

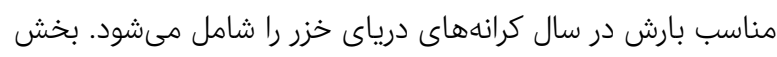

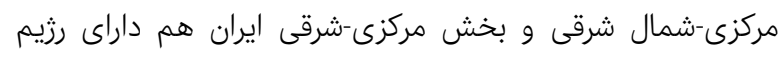

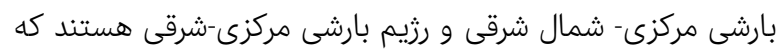

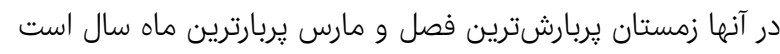

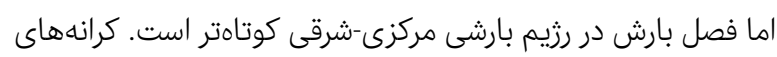

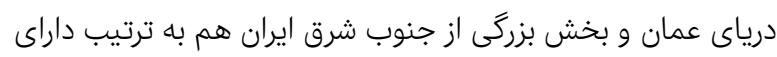

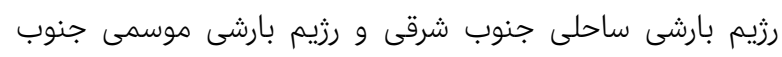

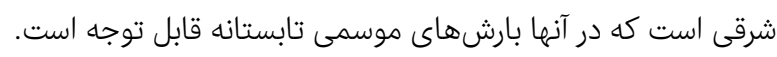

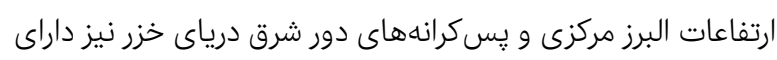

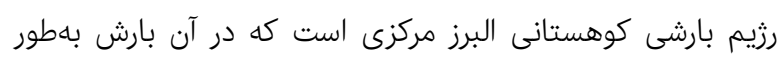

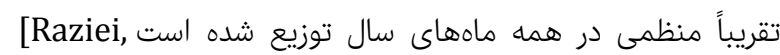

بررسى يزوهشهاى انجام گرفته در كشور نشان مىدهد كه مطالعه

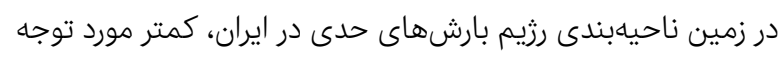

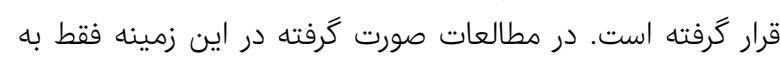

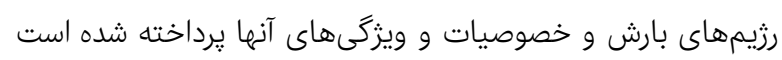

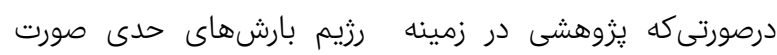

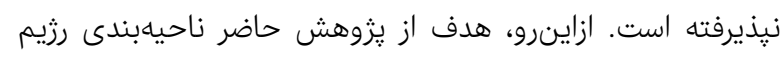

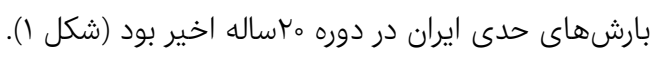

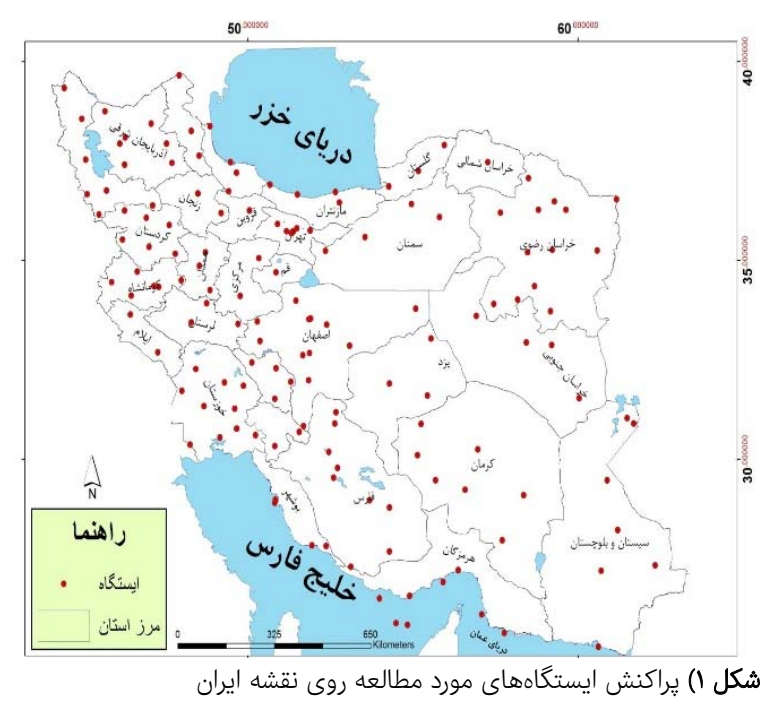

ويزگگهاى بارشى تقسيم كنند [Dinpashoh et al, 2004]. رضيئى و همكاران [Raziei et al, 2008] نيز با تحليل مؤلفههاى

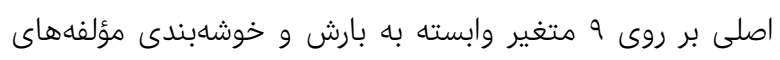

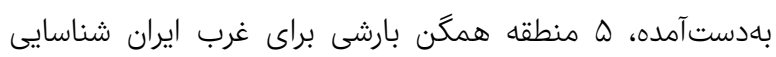

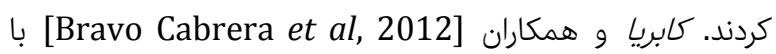

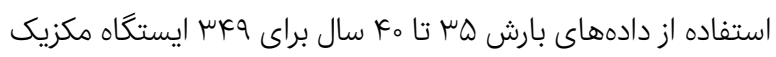

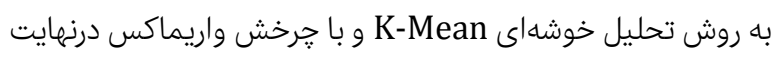

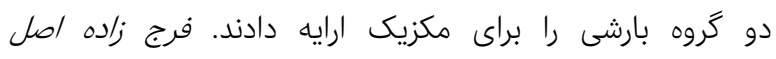

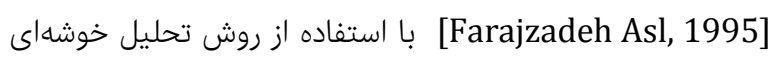

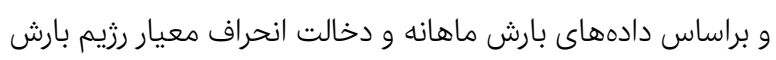

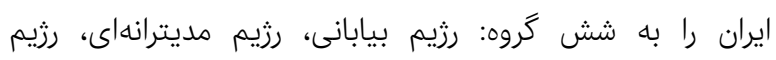

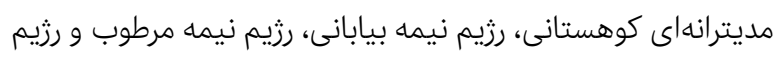

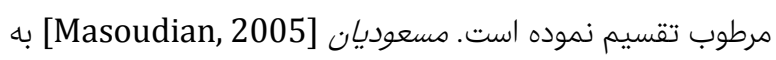

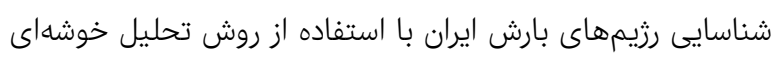

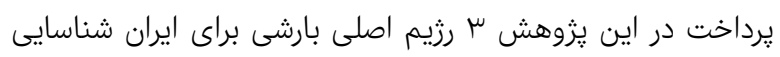

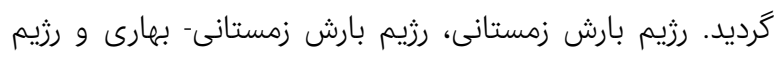

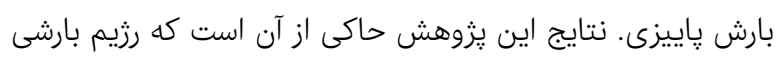

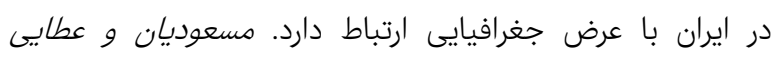

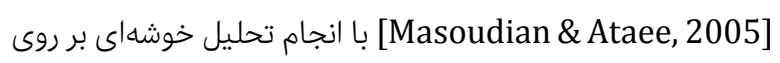
نيم سده ماهانه ايران ه ناحيه بارشى شناسايى كردهاند. مدرس و

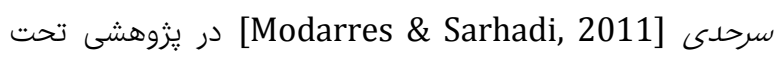

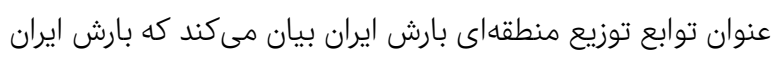

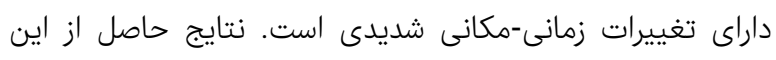

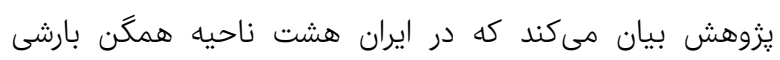

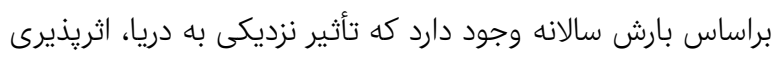

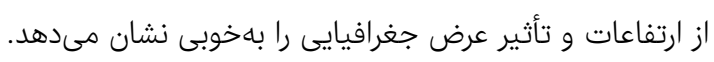

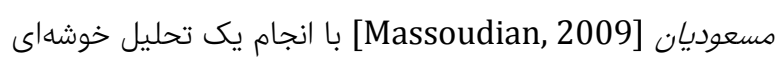

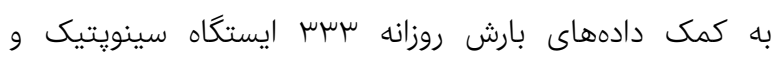

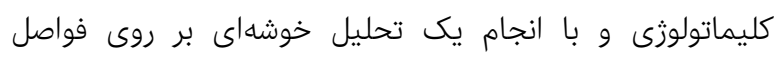

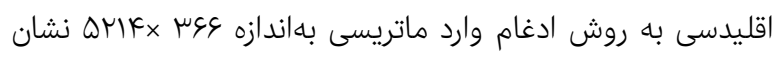

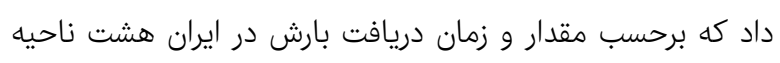

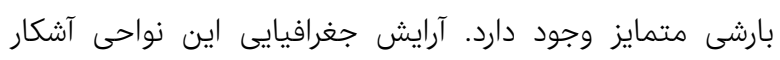

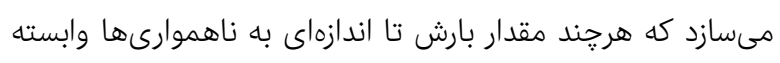

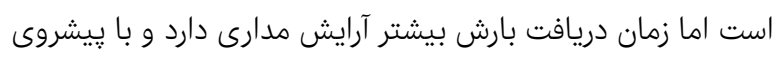

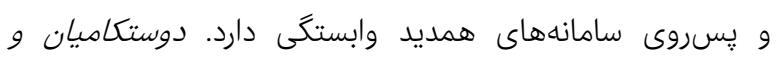

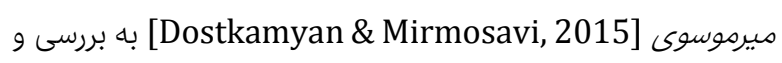

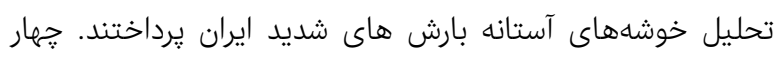

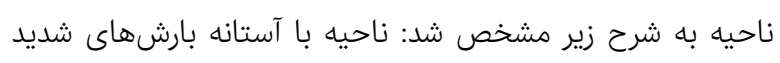

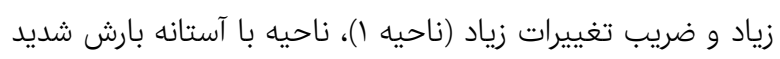

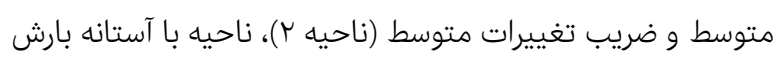

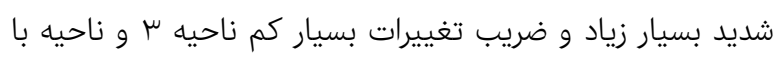

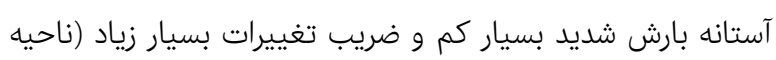

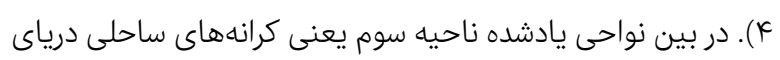
خزر داراى بالاترين آستانه بارشهاى شاحيه شديد بوده است اين درائ در حالى درياي 
معمولاً از ماتريس همبستخى يا ماتريس هم يراش بين متغيرها

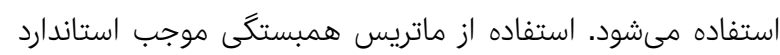

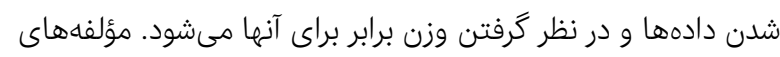

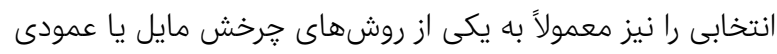

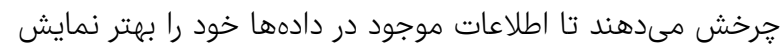

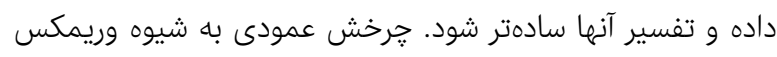

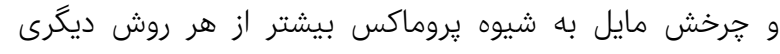
استفاده مىشود [Richman, 1981]. در ميان اقليم شناسان تعريف يكسانى از روزهاى بارشى وجود ندارد. سامر و كايجارو

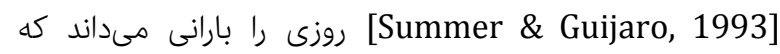
دستكم /ه ميلىمتر بارش داشته باشد. دومروس و رو راناتونكً

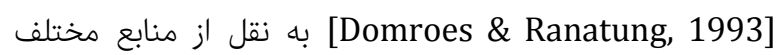

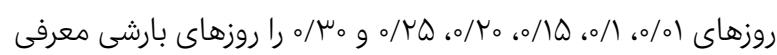

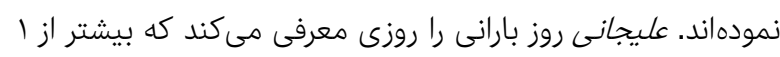

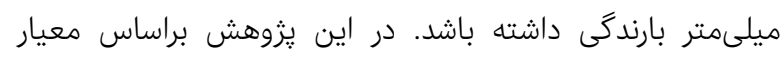

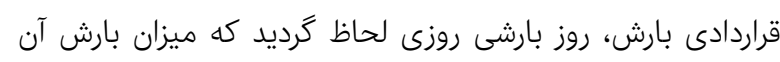

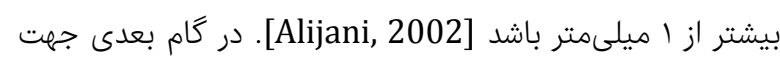

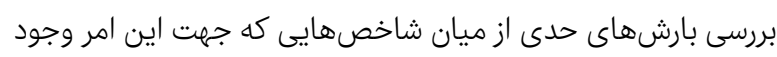

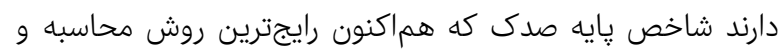

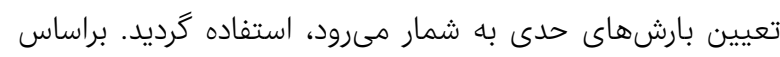

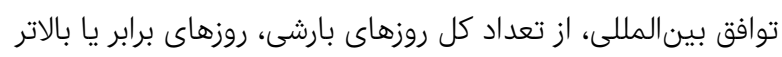

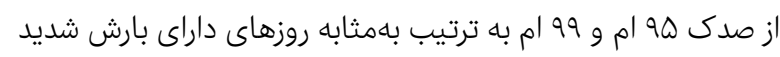

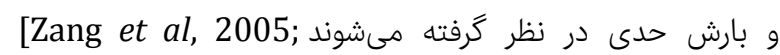
Alexander et al, 2006; [Peterson et al, 2001

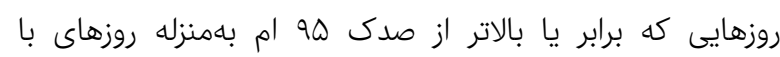

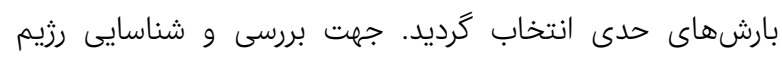

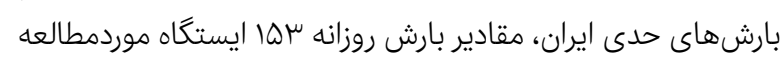

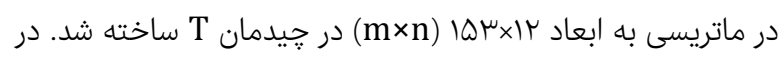

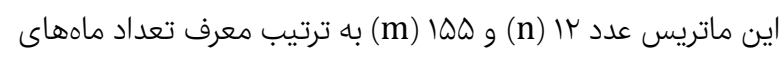

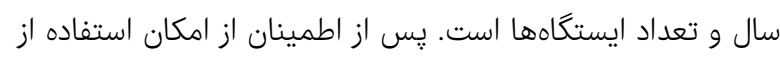

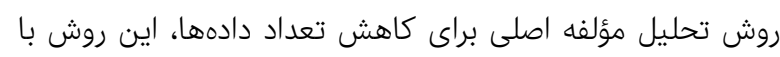

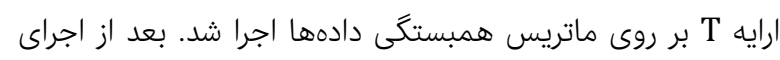

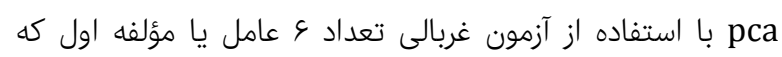

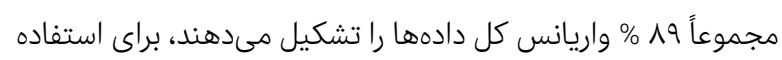

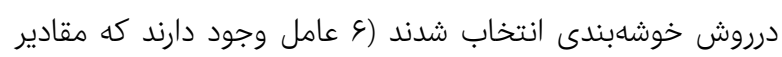

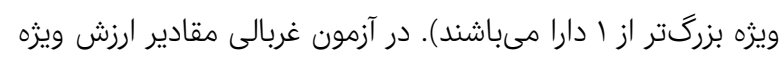

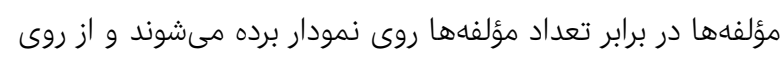

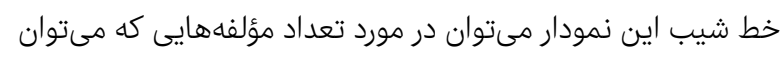

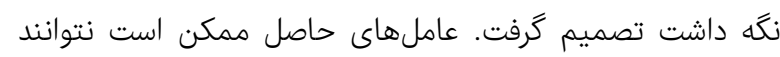

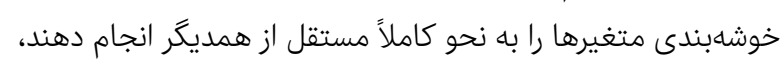

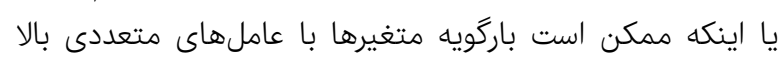

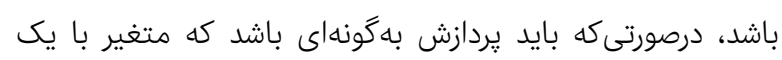

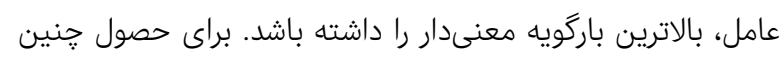

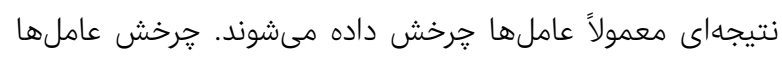

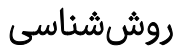

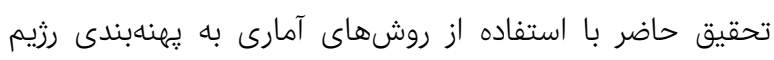

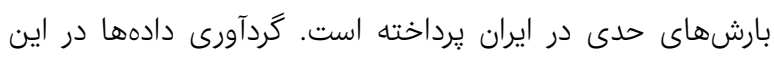

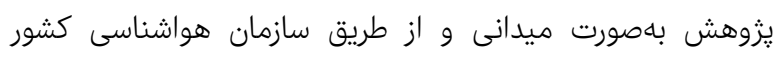

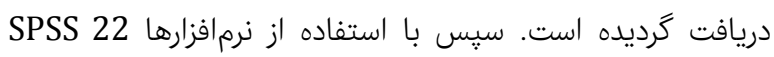

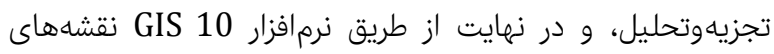

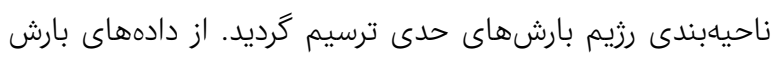

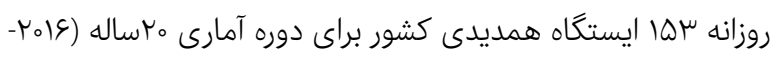
1999) كه از سازمان هواشناسى كشور تهييه كرديد، استفادها

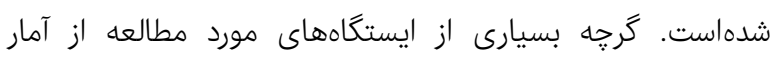

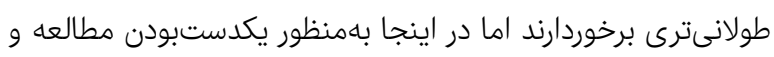

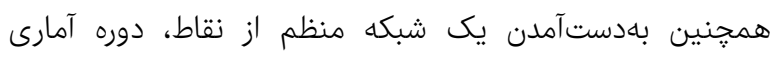

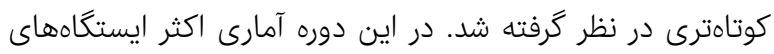

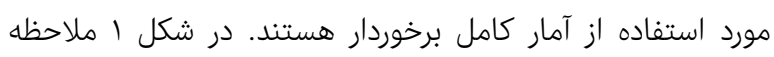

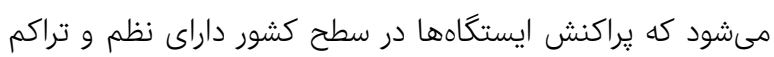

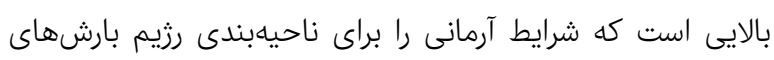

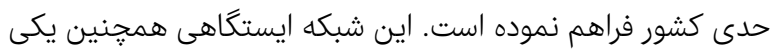

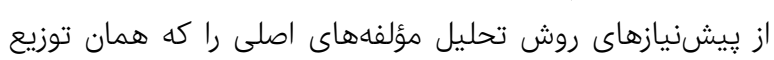

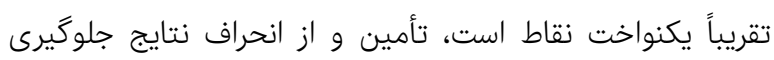

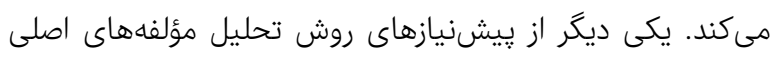

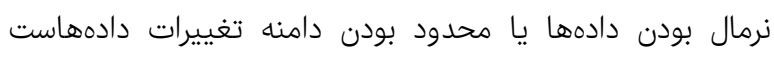

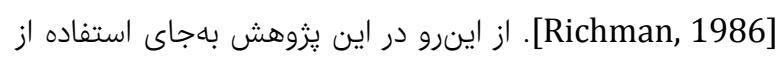

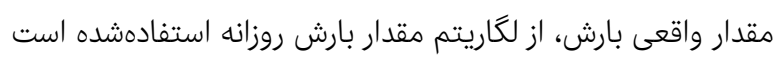

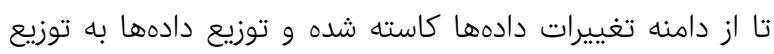

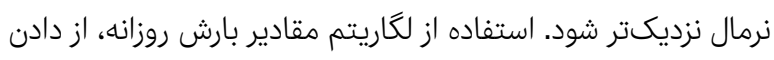

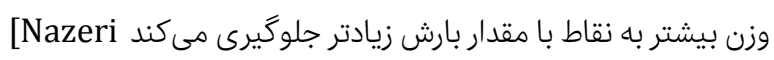

.Tohroodi et al, 2013; Raziei, 2017]

تحليل مؤلفه اصلى

تحليل مؤلفههاى اصلى و خوشهبندى از جمله روشهايى هستند

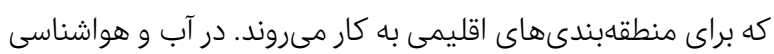

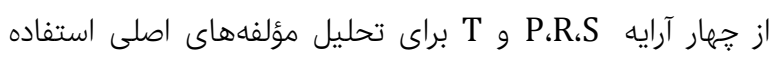

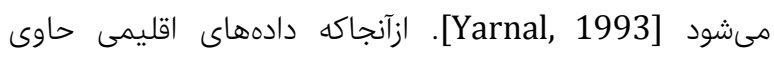

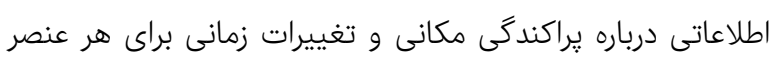

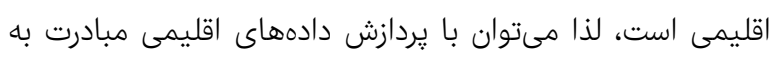

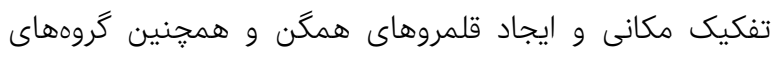

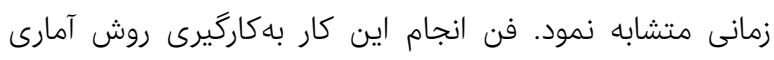

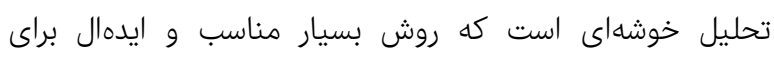

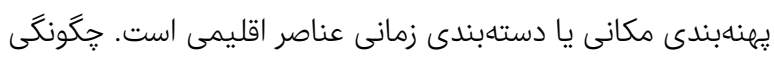

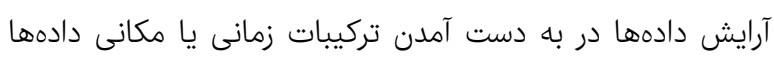

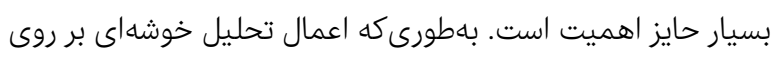

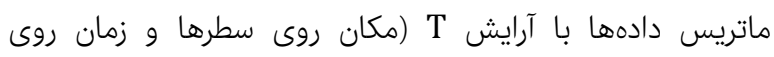

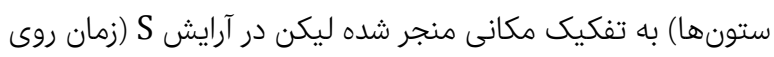

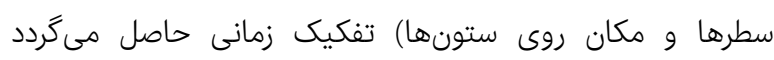
[Masoudian \& Ataee, 2005] براى تحليل مؤلفهانهاى اصلى مانى 


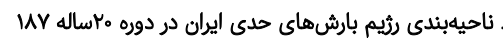

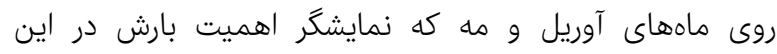

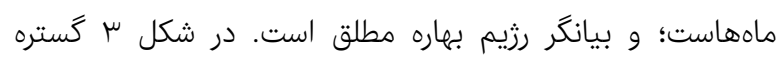

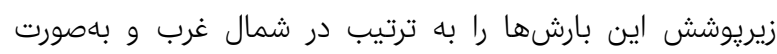

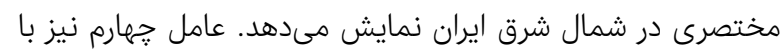

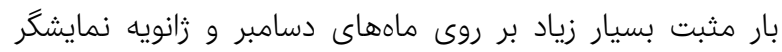

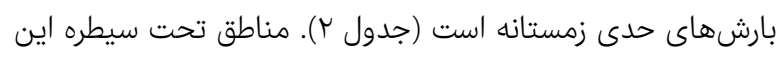

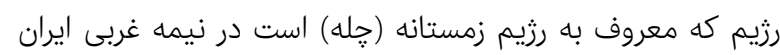

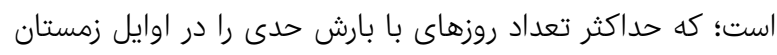

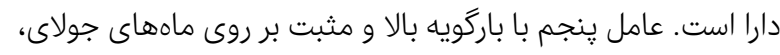

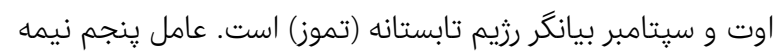

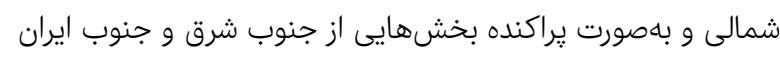

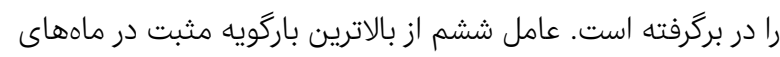

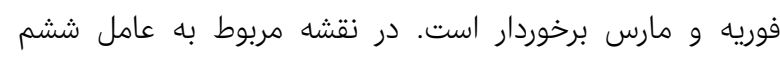

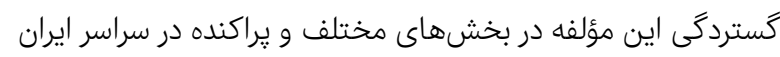

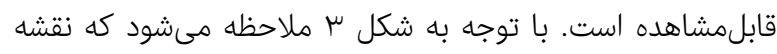

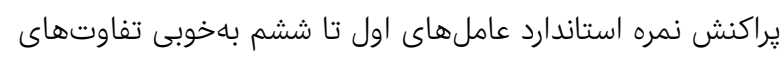

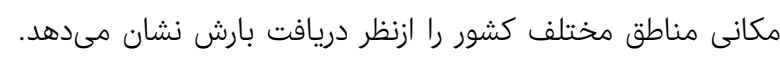

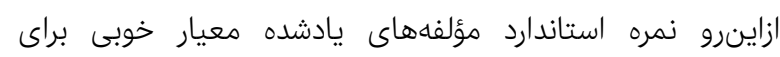

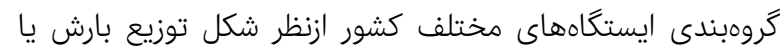

$$
\text { رزيم بارشى هستند. }
$$

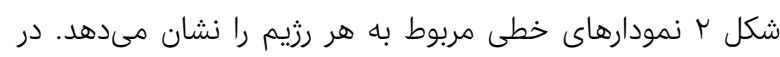

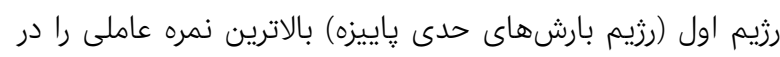

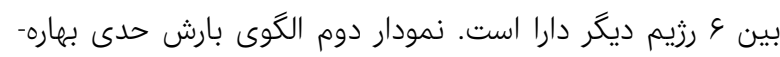

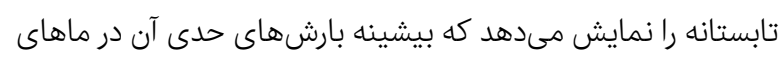

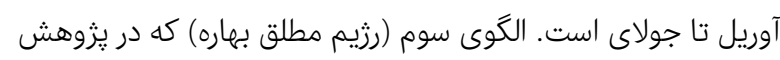

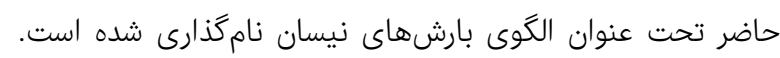

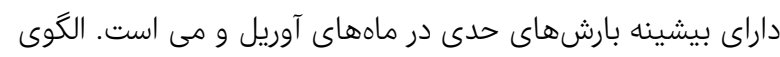

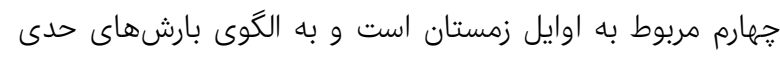

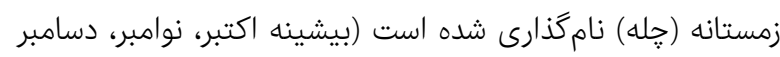

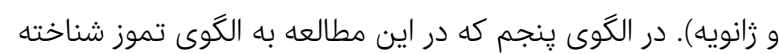

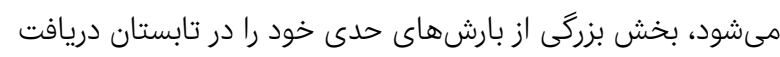

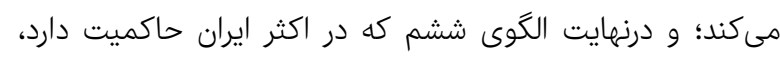
حداكثر بارشهاى حدى اين رزيم در زمستان (مارس) است.

\begin{tabular}{|c|c|c|c|c|c|c|}
\hline عامل ششم & عامل پِنجم & عامل جهارم & عامل سوم & عامل دوم & عامل اول & ماه \\
\hline & & ס/A૬ & & & & ثرانويه \\
\hline$\circ / 90$ & & & & & & فوريه \\
\hline \multirow[t]{10}{*}{.$/ 9 V$} & & & & & & مارس \\
\hline & & & $\circ / q_{0}$ & & & آوريل \\
\hline & & & $\cdot / \Delta \Lambda$ & $0 / 99$ & & مه \\
\hline & & & & س & & ز روئن \\
\hline & -/DG & & & $0 / 9 V$ & & جولاى \\
\hline & $\circ / 90$ & & & & & اوت \\
\hline & - $/ \Delta R$ & & & & $\circ / \mathrm{V} \Lambda$ & سيتامبر \\
\hline & & & & & 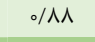 & اكتبر \\
\hline & & & & & $\circ / \wedge \Delta$ & نوامبر \\
\hline & & O/AY & & & & دسامبر \\
\hline
\end{tabular}

[Alijani, معمولاً به دو صورت عمودى و مايل انجام مى

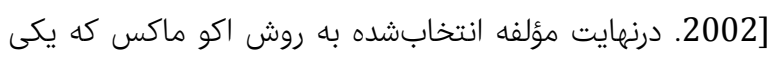

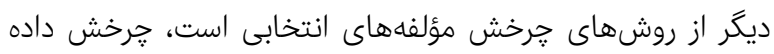
شد تا ساختار موجود در دادهها بهتر شناسايى شود. جدول

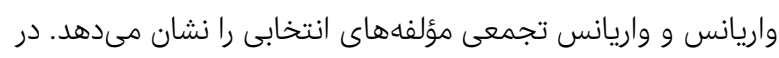

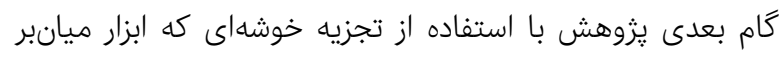

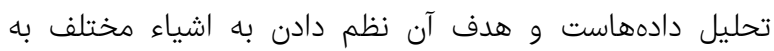

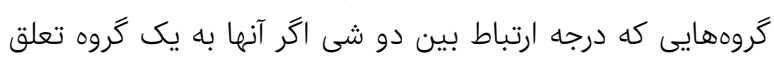

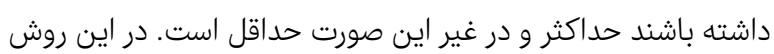

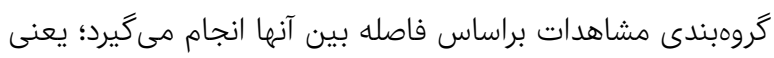

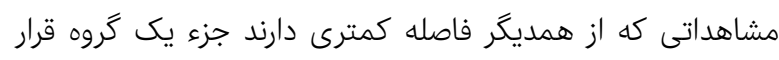

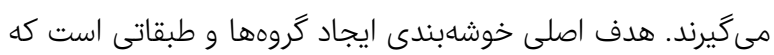

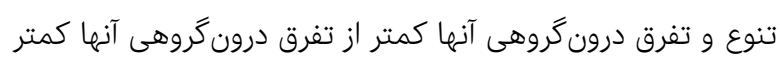

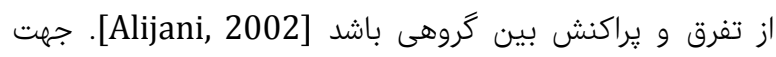

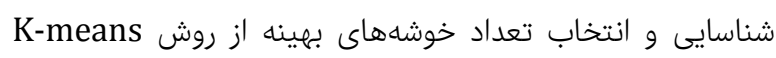

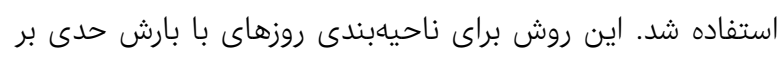

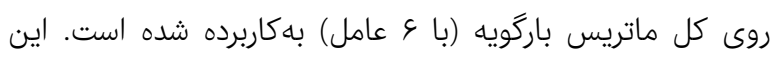

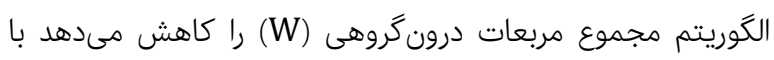

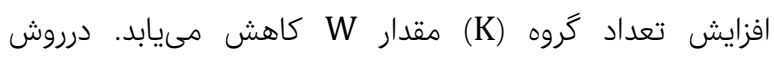

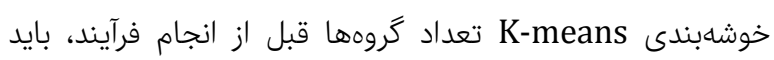

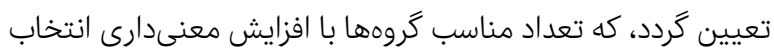

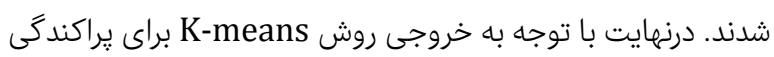
رزيم بارشهاى حدى در ايران ^ رزيم بارش حدى شناسايى شد.

\begin{tabular}{|c|c|c|c|c|c|c|}
\hline \multicolumn{3}{|c|}{ جرخش به شيوه اكواماكس } & \multicolumn{3}{|c|}{ بدون جرخش } & \multirow[b]{2}{*}{ عاملها } \\
\hline تجمعى & 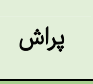 & بار عاملها & تجرعى & 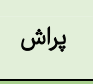 & بار عاملها & \\
\hline 19/VEr & 19/VEY & $r / \mu V I$ & $\mu \mathrm{M} / \mathrm{V} \omega$ & $\mu \mathrm{J} / \mathrm{N} \boldsymbol{\omega}$ & $\mu / \Lambda \circ \Lambda$ & اول \\
\hline 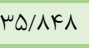 & $\mid \varepsilon / 0 \wedge \varepsilon$ & $1 / 9 \mu$ 。 & QH/NKS & $r / \Delta I$ & $r / \Delta \wedge 1$ & 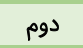 \\
\hline$k q / 9 k \mu$ & $1 \% / V 9 \Delta$ & 1/9๑Q & $V Y / 9 K \Delta$ & $11 / 999$ & r/TKK & 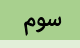 \\
\hline$\varepsilon \mu / k \mid V$ & IF/VVF & 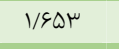 & 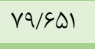 & $V / V_{0} S$ & ॰/ArQ & جهارم \\
\hline$V V / \circ V V$ & $|\Psi / 99|$ & 1/दmq & $\Lambda Q / \Delta Q F$ & $\Delta / \Delta .9$ & $\circ / V_{0} \Lambda$ & ل ينجم \\
\hline ^৭/६०। & $I T / \mu V K$ & I/FAD & $\wedge q / F \Delta ।$ & 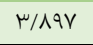 & $0 / 4 \& \Lambda$ & مشم \\
\hline
\end{tabular}

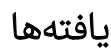

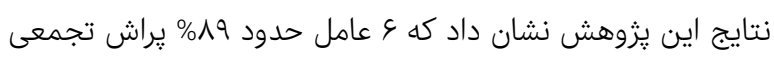

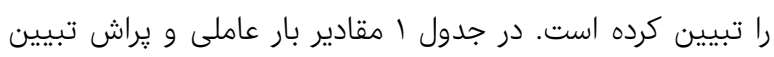

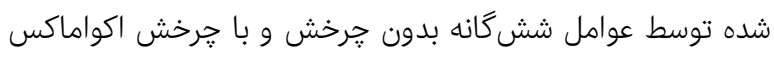

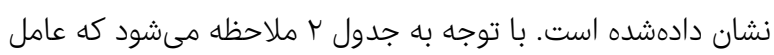

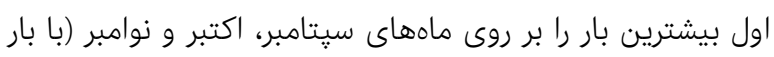

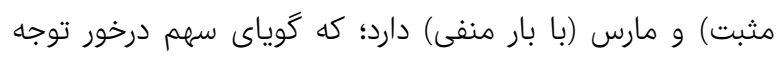

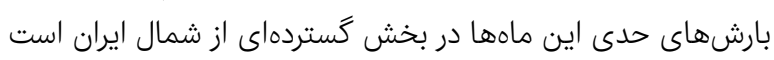

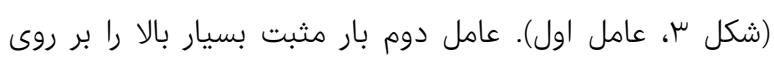

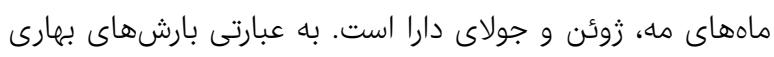

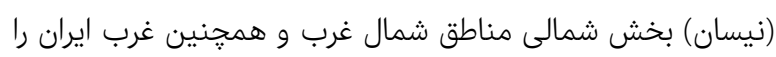

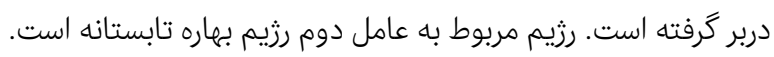

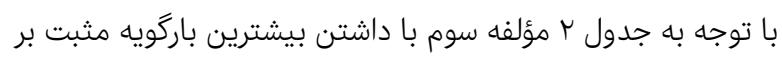



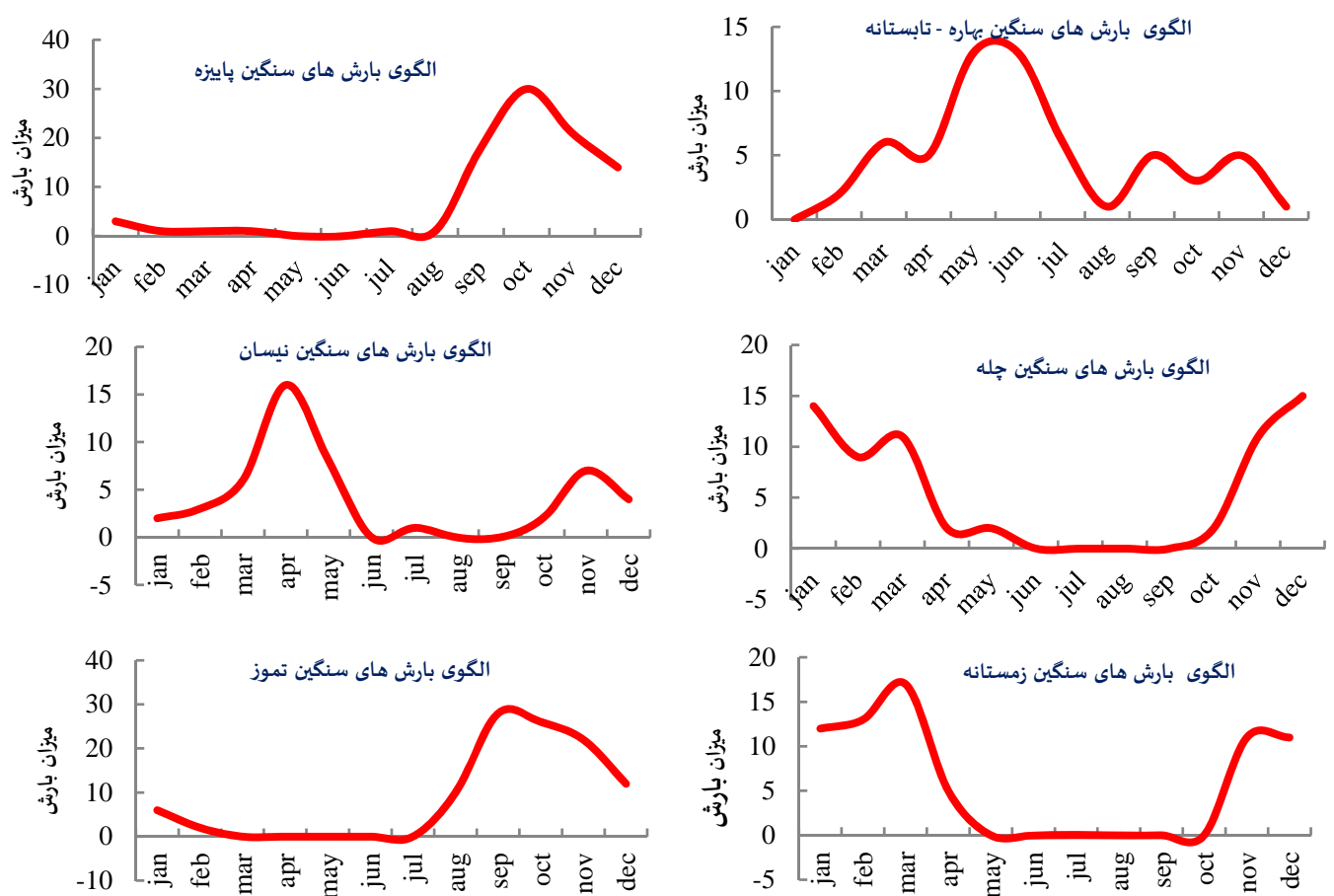

شكل r) الكَى بارشهاى حدى ايران

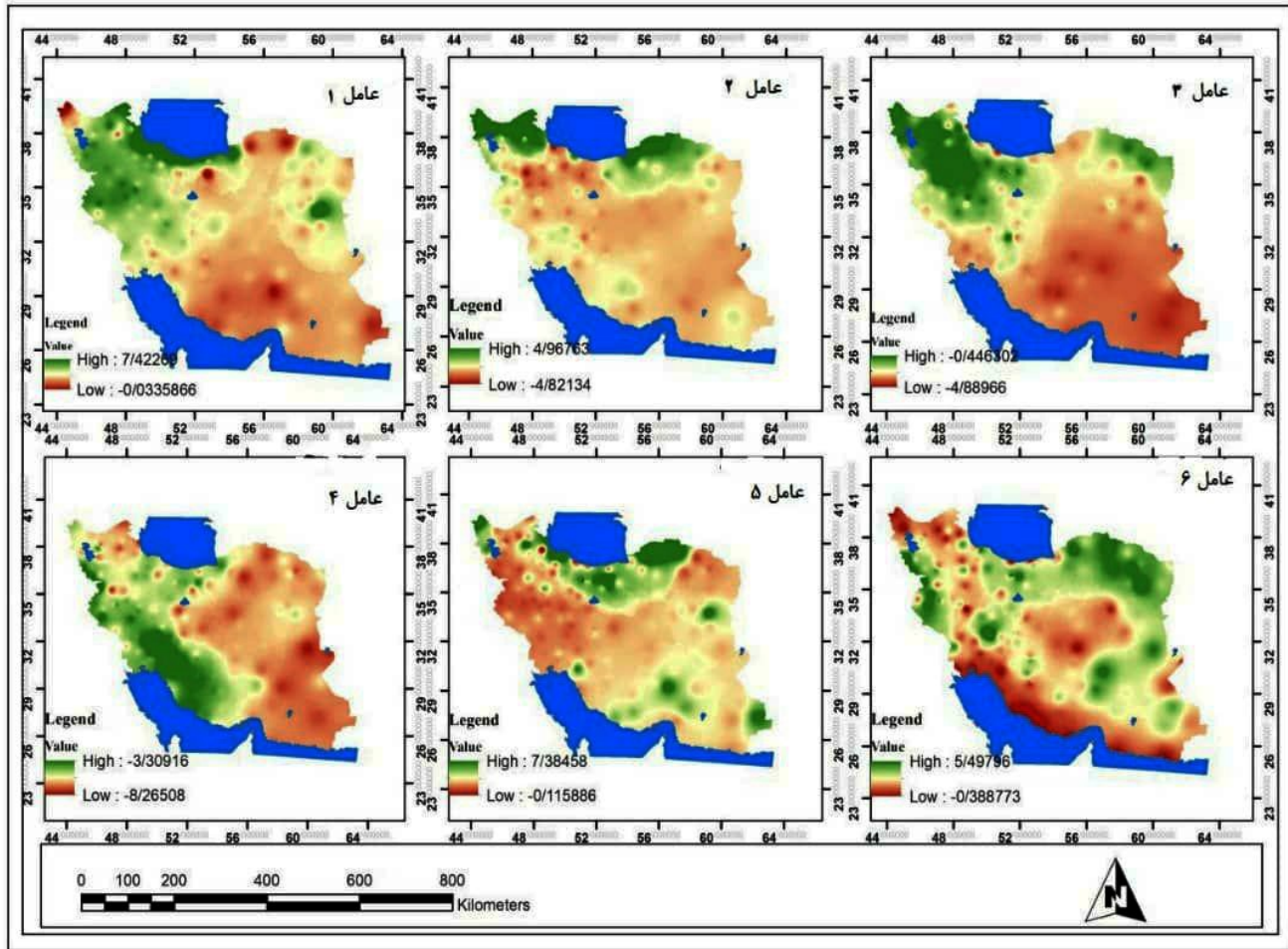

شكل س) توزيع مكانى نمره استاندارد مقادير مؤلفههاى اول تا ششم پس از جرخش به شيوه اكواماكس

يراكندگى جغرافيايى قلمرو اين رزيمها در شكل شماره ه به نمايش كذاشته شدهاست.

تعداد ه ايستگًاه همديدى استانهاى شمال غرب ايران و استان كلستان در محدوده رزيم بارشهاى حدى البرز شرقى واقعشدهاند.

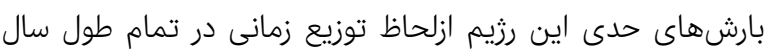

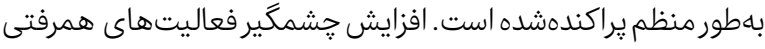

بحث

با توجه به اينكه ايران در منطقهاى خشك واقع شدهاست تغييرات

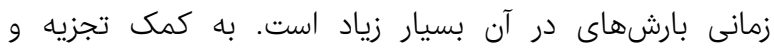

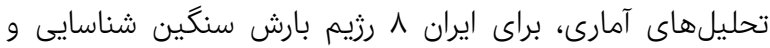

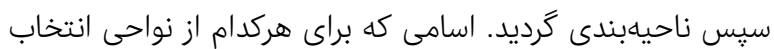
گرديده است برگرفته از موقعيت جغرديدافيايى اين رزيمها است. 


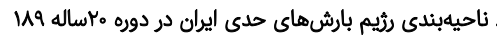

اين رزيم با شرايط جغرافيايى اين بخش از ايران است كه ميتوان التردان

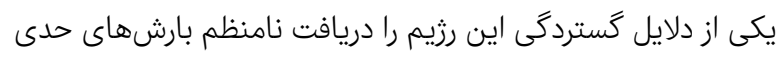

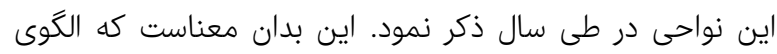

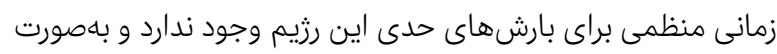

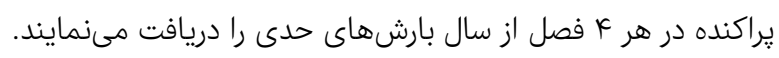

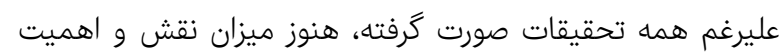

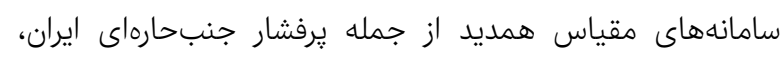

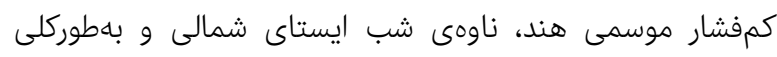

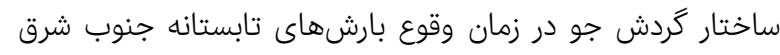

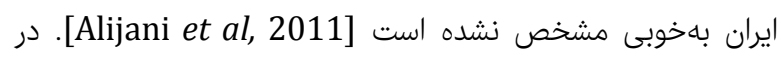

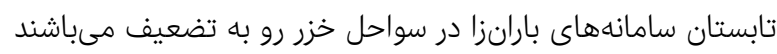

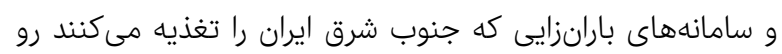

به تقويت مىباشند.

\begin{tabular}{|c|c|c|c|c|c|}
\hline بهاره & تابستانه & ياييزه & زمستانه & نام رثيم & رديف \\
\hline ro & 17 & $\mu_{\Lambda}$ & MI & البرز شرقى & 11 \\
\hline$\varepsilon$ & V & $V_{\circ}$ & 11 & خزرى & $r$ \\
\hline$\mu_{\Lambda}$ & $r$ & 10 & 0. & خشك مركزى - شرق - سواحل جنوب & $\mu$ \\
\hline or & $\wedge$ & ro & $1 \varepsilon$ & آذربايجانى & $\bar{T} \varepsilon$ \\
\hline$\varepsilon V$ & $r 7$ & 11 & 9 & آذربايجان شمالى & 1 \\
\hline$\mu$ & 。 & IV & or & زاگرس ميانى & ; 7 \\
\hline$r_{0}$ & 1 & 11 & 71 & زاگرس جنوبى & ; V \\
\hline$\varepsilon 7$ & $r$ & $r_{0}$ & r & كوهستانى & $\Lambda$ \\
\hline
\end{tabular}

و درنتيجه وقوع بارشهاى اروكرافيك سبب افزايش رقم قابلتوجه

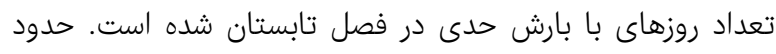

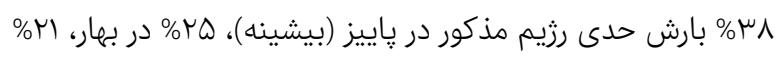

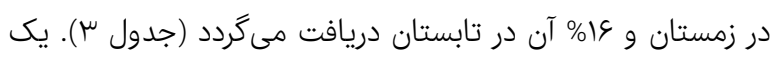

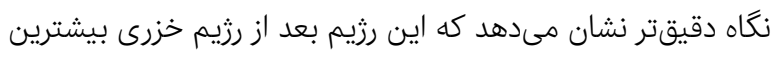

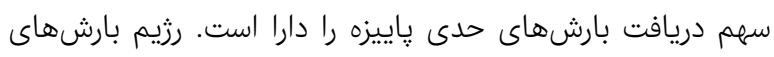

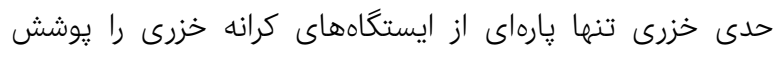

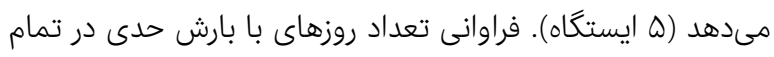

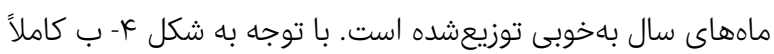

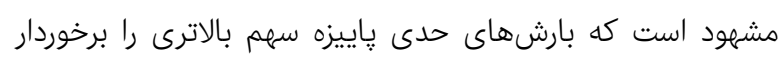

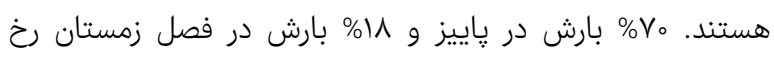

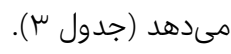

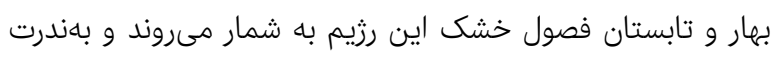

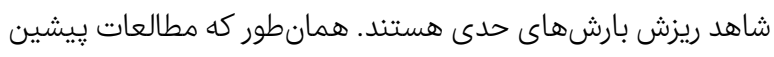

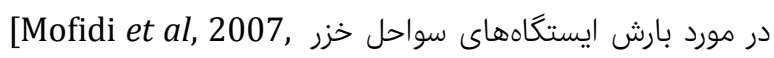
Janbaz Ghobadi et al, 2011; Ghayor et al, 2011] واضح بيان نمودهاند كه فصل پإييز فصل يربارش اين نواحى است.

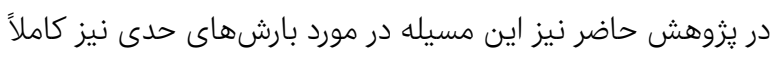

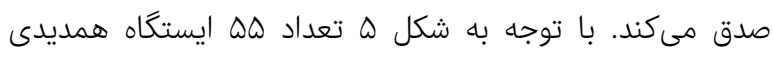

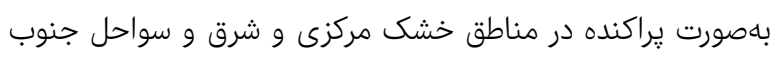

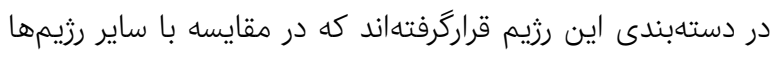

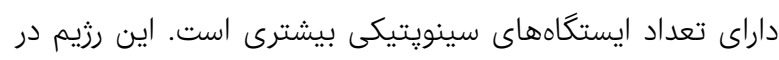

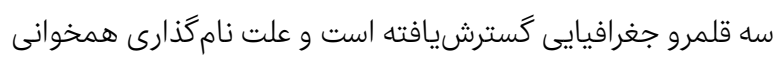
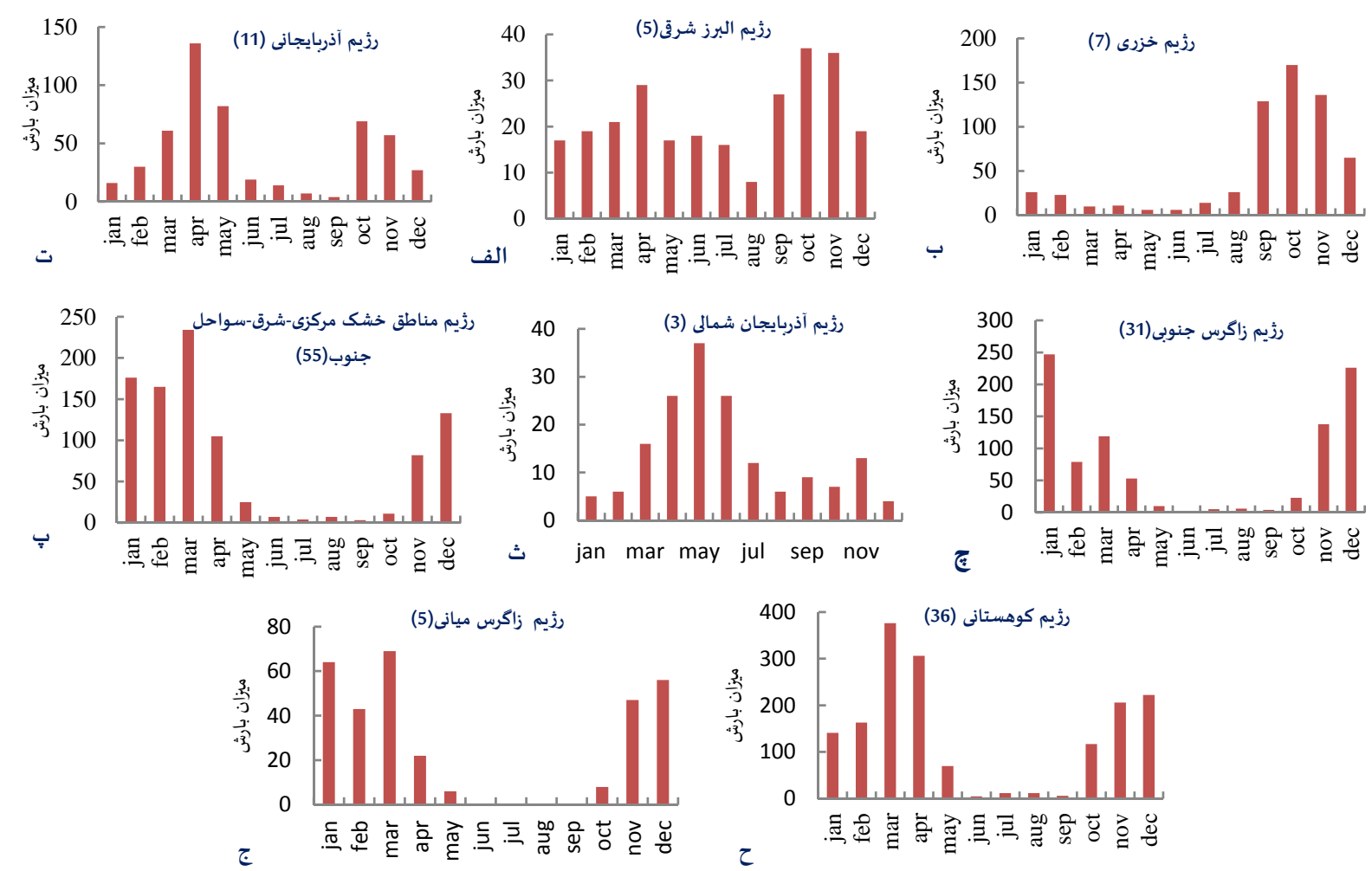

شكل F) رثيمهاى بارشى شناسايىشده ايران، اعداد داخل يرانتز معرف تعداد ايستكاهها در هر رزيم مىباشند 


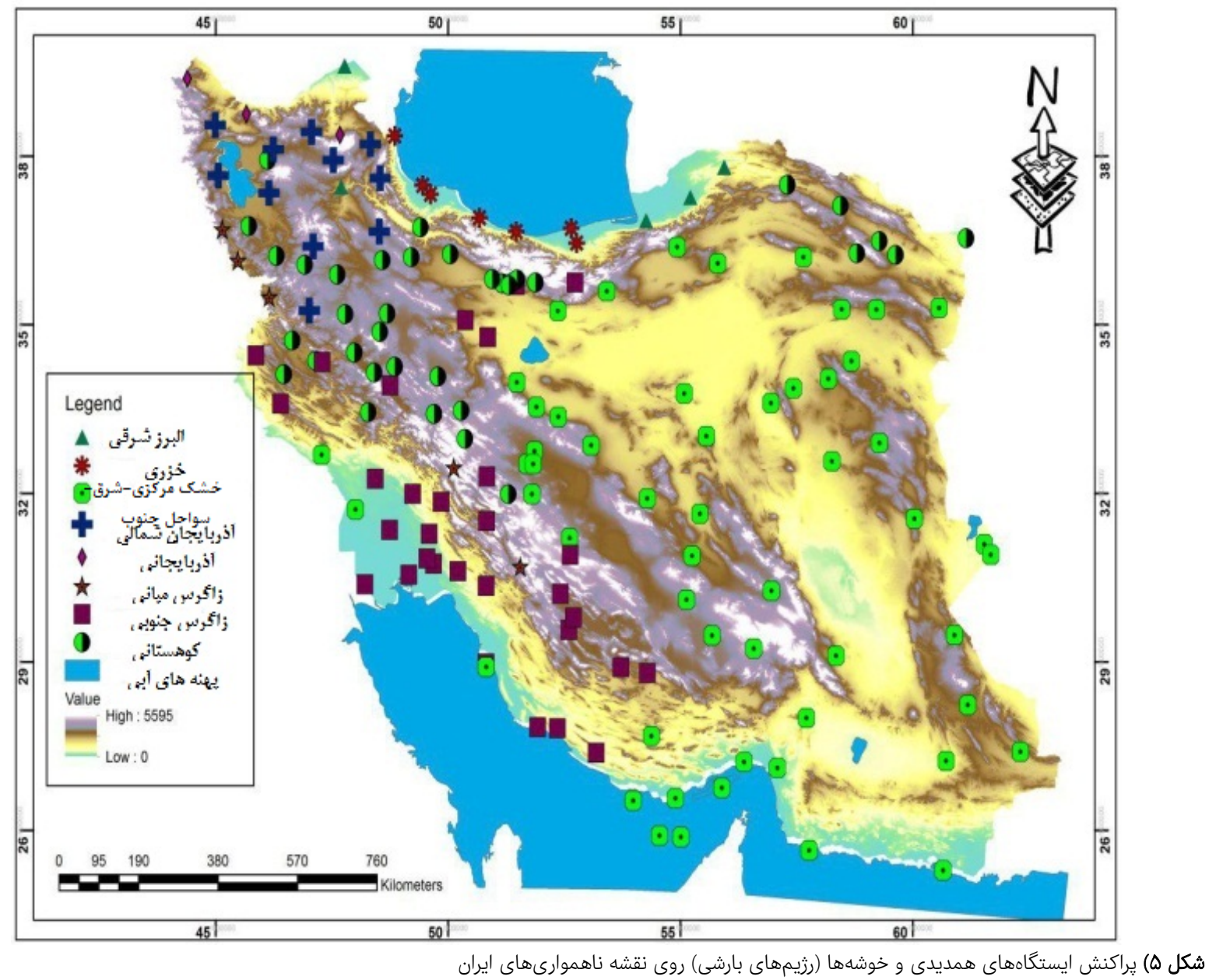

درنتيجه وقوع بارشهاى اروكرافيك سبب افزايش فراوانى بارشهاى

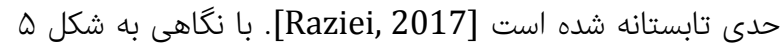

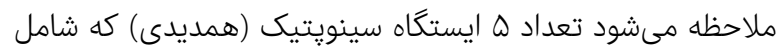

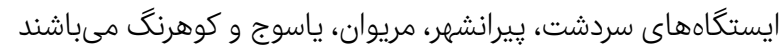

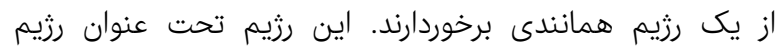

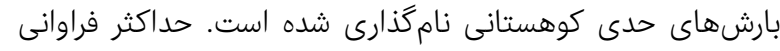

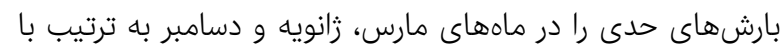

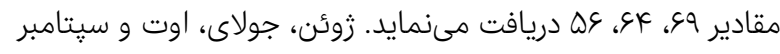

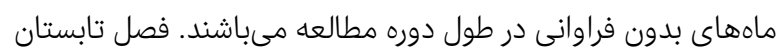

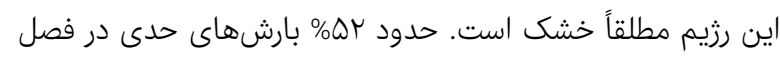

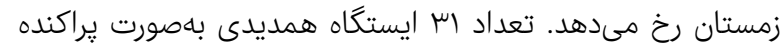

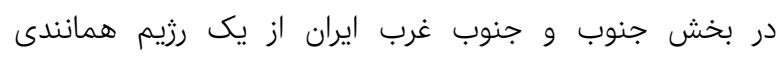

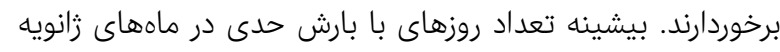

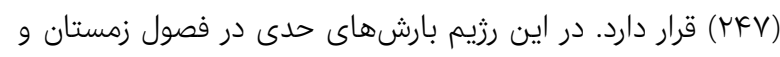

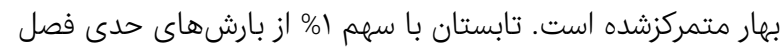

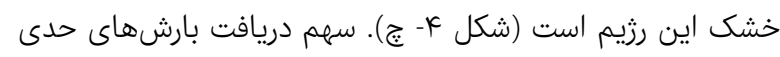

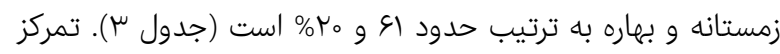

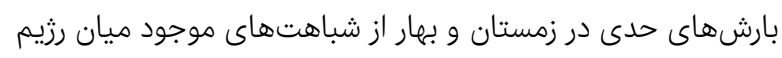

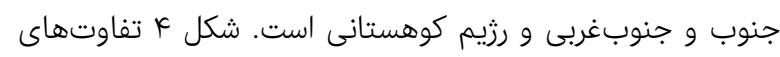

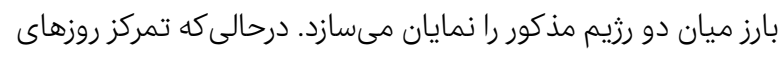

زانويه و فوريه به نسبت تقريباً برابر، فراوانى بارشهاى حدى را رال

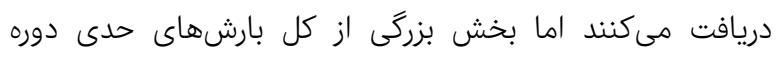

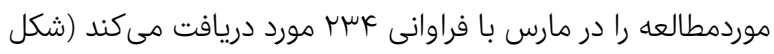

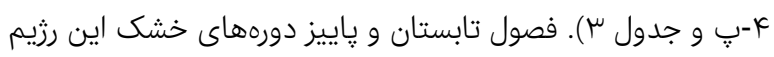

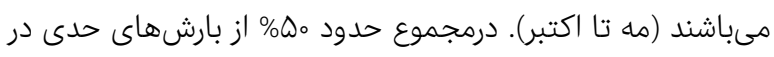

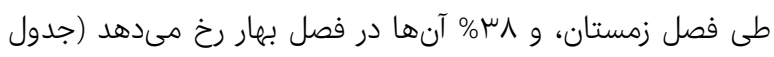

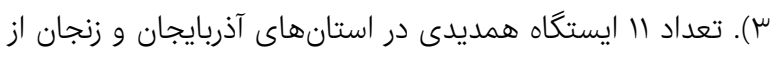

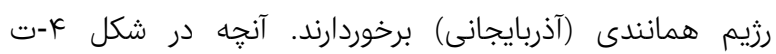

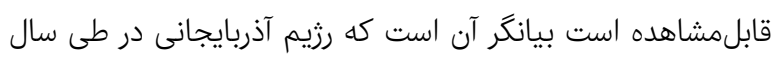

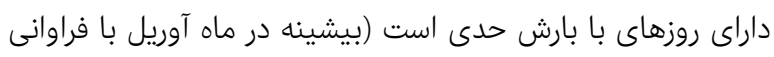

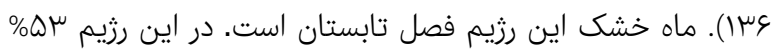

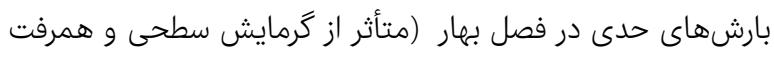

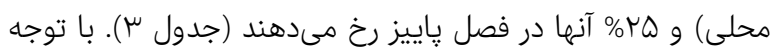

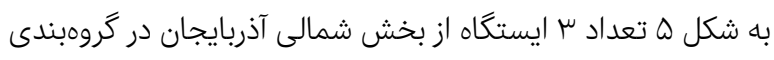

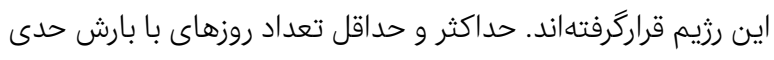

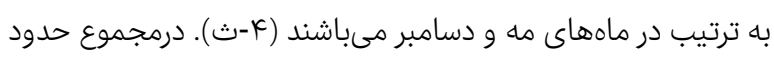

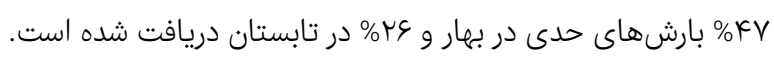

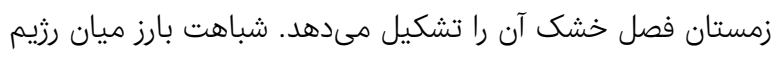

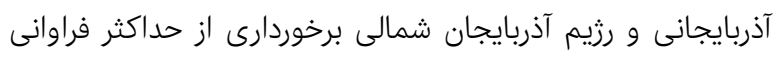

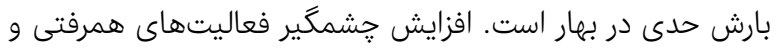


نتيجه گثيرى

هشت رزيم بارش حدى خزرى (سواحل خزر)، آذربايجان شمالى آلى آدريجاني

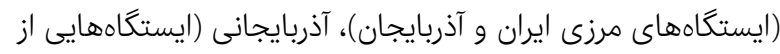

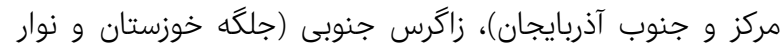

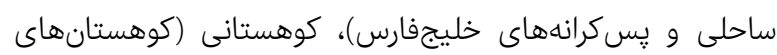

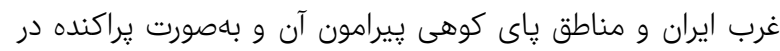

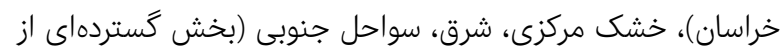

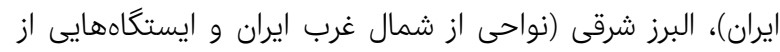

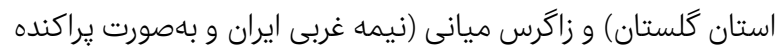

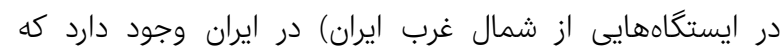

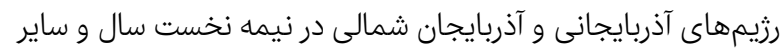

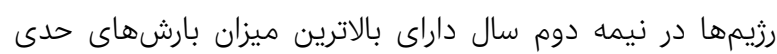

هستند.

تشكر و قدردانى: موردى از سوى نويسندكان كزارش نشده است.

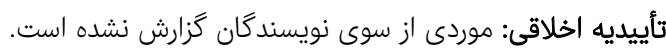

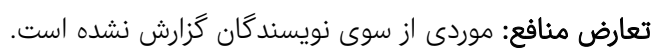

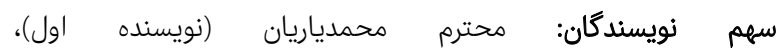

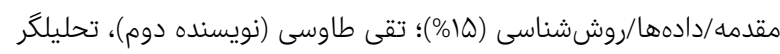

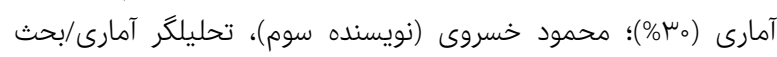

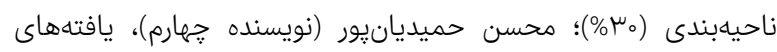

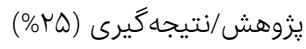
منابع مالى: مقاله حاضر مستخرج از رساله دوره دكترى است.

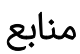

Alexander L, Zhang X, Peterson TC, Caesar J, Gleason B, Klein Tank AMG, et al (2006). Global observed changes in daily climate extremes of temperature and precipitation. Geological Research, Atmosphere. 111(D5).

Alijani B (2001). Iran rainfall hydrometeorology. Scientific Information Center (Virtual). 1(1):261-275. [Persian]

Alijani B, Mofidi A, Aliakbari Bidokhti A, Jafarpour Z (2011). Atmospheric circulation patterns of the summer rainfalls in the southeast Iran during July 1994. Earth and Space Physics. 37(3):205-227. [Persian]

Alijani B (2002). Synoptic climatology. $1^{\text {st }}$ Edition. Tehran: Samt Publication. [Persian]

Dinpashoh Y, Fakheri-Fard A, Moghaddam M, Jahanbakhsh S, Mirnia M (2004). Selection of variables for the purpose of regionalization of Iran's precipitation climate using multivariate methods. Journal of Hydrology. 297(1-4):109-123.

Domroes M, Ranatung E (1993). A statistical approach toward a regionalization of daily rainfall in Srilanka. Climatology. 13(7):741-754.

Domroes M, Kaviani M, Schaefer D (1998). An analysis of regional and intra-annual precipitation variability over Iran using multivariate statistical methods. Climatology. 61(3-4):151-159.

Dostkamyan M, Mirmosavi SH (2015). The study and analysis the clusters of heavy rainfall threshold in Iran. Geography and Development. 13(41):131-146. [Persian]
با بارش حدى در رزيم جنوب جنوب غربى در زمستان است (رزيم

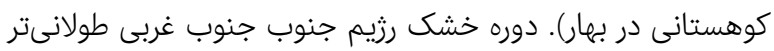

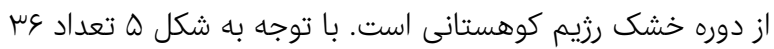

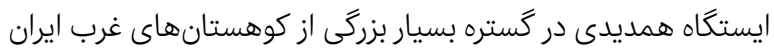

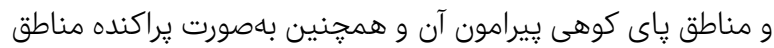

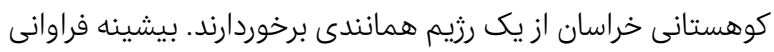

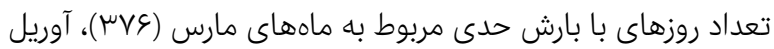

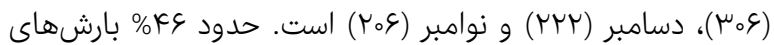
حدى اين رزيم در فصل بهار و r世\% در فصل زمستان اتفاق مىافتد (جدول س). درمجموع، بررسىها نشان داد كه بيشترين ور كمتر درين

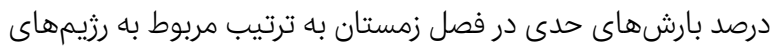

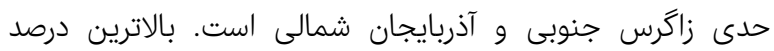

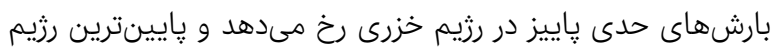
بارش حدى فصل ياييز مربوط گستره رزيم خشك مركزى

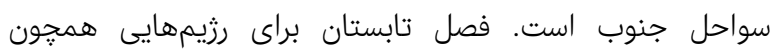
آذربايجان شمالى و البرز شرقى بارشهاى حدى فـى نسبتاً بالايى را در

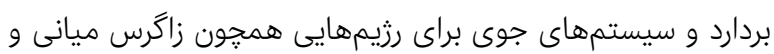

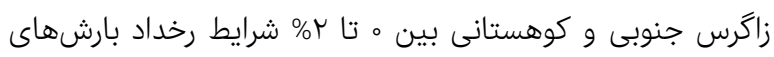

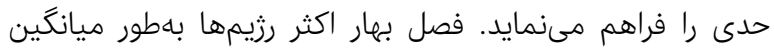
حدود سر\% بارشهاى حدى را دريافت مىنمايند كه دراين بين

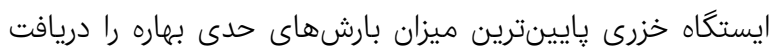

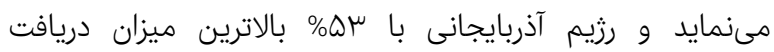
بارشهاى بهاره را دارا است. نتايج حاصل از ارزيابى و شناسايى رزيم بارشهاى حدار حدى نشان از از

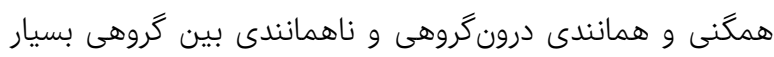

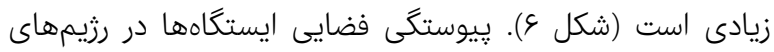

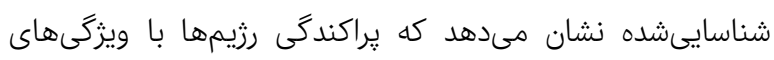

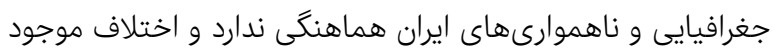

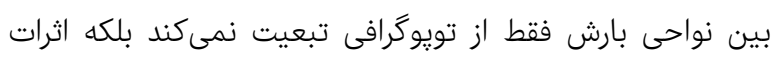

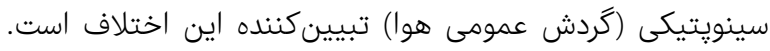

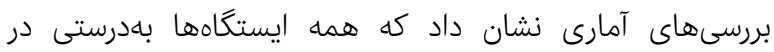

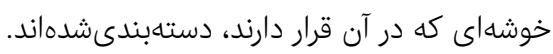

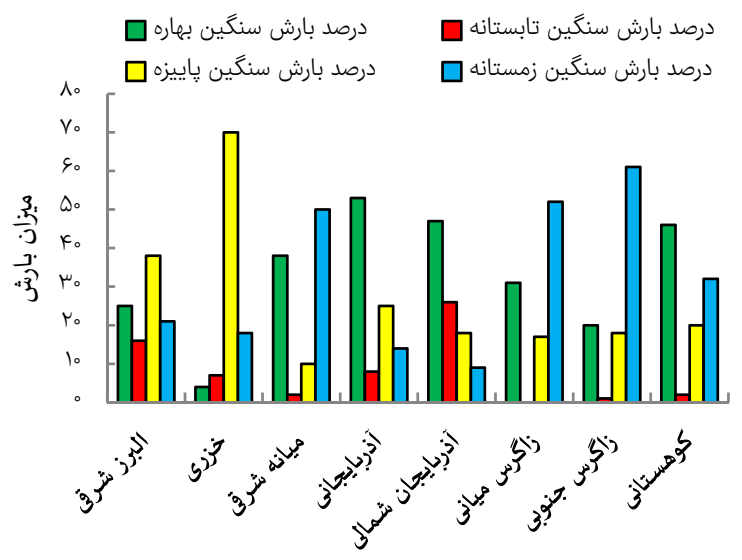

شكل \&) توزيع فصلى بارشهاى حدى در رزيمهاى مختلف بارشهاى حدى 
Peterson TC, Folland C, Gruza G, Hogg W, Mokssit A, Plummer N (2001). Report on the activities of the working group on climate change detection and related rapporteurs 1998-2001. Geneva: World Meteorological Organization.

Raziei T (2017). Identification of precipitation regimes of Iran using multivariate methods. Earth and Space Physics. 43(3):695-673. [Persian]

Raziei T, Bordi I, Pereira LS (2008). A precipitation-based regionalization for western Iran and regional drought variability. Hydrology and Earth System Sciences. 12:1309-1321.

Raziei T, Azizi G (2007). The zoning of the western rainforest regime using principal component analysis and clustering methods. Iran-Water Resources Research. 3(2):46-49. [Persian]

Regenmortel GV (1995). Regionalization of Botswana rainfall during the 1980s using principal component analysis. International Journal of Climatology. 15(3):313323.

Raziei T (2017). Identification of Iranian rainfall regimes using multivariate methods. Earth and Space Physics. 43(3):695-673. [Persian]

Richman MB (1986). Rotation of principal components. Climatology Banner. 6(3):293-335.

Seibert P, Frank A, Formayer H (2007). Synoptic and regional patterns of heavy precipitation in Austria. Theoretical and Applied Climatology. 87(1-4):139-153.

Yarnal B (1993). Synoptic climatology in environmental analysis: A primer [Book Review]. Climatology. 14(1):115.

Zhang X, Aguilar E, Sensoy S (2005). Trends in Middle East climate extreme indices from 1950 to 2003. Atmosphere. 110(D22).

Summer G, Ramis G, Guijaro J (1993). The spatial organization of daily rainfall over Mallorca, Spain. Climatology. 13(1):89-109. 19r

Farajzadeh-Asl M (1995). Drought analysis and forecasting in Iran [Dissertation]. Tehran: Tarbiat Modares University.

Ghayoor HA, Masoudian SA, Azadi M, Noori H (2011). Analysis of temporal and spatial events of the Caspian Sea coastal events. Geographical Researches Quarterly Journal. 100(26):1-30. [Persian]

Janbaz Ghobadi Gh, Mofidi A, Zarrin A (2011). Identify the patterns of severe winter rainfall in the southern coastal of the Caspian Sea. Geography and Environmental Planning. 22(2):23-40. [Persian]

Masoodian A (2005). Identification of Iran's rainfall regime by cluster analysis. Geographical Research. 37(52):47-59. [Persian]

Masoodian A (1998). Investigating the system of temporal and spatial variations of rainfall in Iran [Dissertation]. Isfahan: Isfahan University. [Persian]

Masoudian SA, Ataee H (2005). Identification of Iranian rainfall season by cluster analysis. Applied Sociology. 18(1):12-1. [Persian]

Masoodian A (2009). Precipitation regions of Iran. Geography and Development. 7(13):79-91. [Persian]

Modarres R, Sarhadi A (2011). Statistically-based regionalization of rainfall climates of Iran. Global and Planetary Change. 75(1-2):67-75.

Mofidi A, Zarrin A, Janbaz Ghobadi GR (2007). Determination of the pattern of extreme and fatal precipitation in the southern costal of the Caspian Sea. Physics of Earth and Space. 33(3):131-154. [Persian] Nazeri Tohroodi M, Khalili K, Abbaszadeh-Afshar M, Nazeri-Torodi Z (2013). Comparison of normalizing conversions to normalize monthly rainfall data in different regions of Iran. Water and Soil. 28(2):365-372. [Persian]

Seibert P, Frank A, Formayer H (2007). Synoptic and regional patterns of heavy precipitation in Austria. Theoretical and Applied Climatology. 87(1-4):139-153. 